\title{
Keynote Talk: The Resurgence of Software Performance Engineering
}

\author{
Charles E. Leiserson \\ MIT Computer Science and Artificial Intelligence Laboratory \\ Cambridge, MA, USA \\ cel@mit.edu
}

\begin{abstract}
Today, most application developers write code without much regard for how quickly it will run. Moreover, once the code is written, it is rare for it to be reengineered to run faster. But two technology trends of historic proportions are instigating a resurgence in software performance engineering, the art of making code run fast. The first is the emergence of cloud computing, where the economics of renting computation, as opposed to buying it, heightens the utility of application speed. The second is the end of Moore's Law, the 50-year technology trend which has, until recently, relentlessly doubled the number of transistors on a semiconductor chip every two years. The end of Moore's Law will cause industry to look beyond semiconductor manufacturers for computing performance. As a result of these two trends, application programmers will increasingly find themselves turning to software performance engineering in order to develop innovative products and applications.
\end{abstract}

\section{CCS CONCEPTS}

- General and reference $\rightarrow$ Surveys and overviews;

\section{KEYWORDS}

Cloud computing; Moore's Law; software performance engineering

\section{ACM Reference Format:}

Charles E. Leiserson. 2018. Keynote Talk: The Resurgence of Software Performance Engineering. In SPAA '18: 30th ACM Symposium on Parallelism in Algorithms and Architectures, fuly 16-18, 2018, Vienna, Austria. ACM, New York, NY, USA, 1 page. https://doi .org/10.1145/3210377. 3210378

\section{BIOGRAPHY}

Charles E. Leiserson received his B.S. from Yale University in 1975 and his Ph.D. from Carnegie Mellon University in 1981. He joined the faculty of MIT in 1981, where he is now the Edwin Sibley Webster Professor in MIT's Department of Electrical Engineering and Computer Science. He is Associate Director and Chief Operating Officer of the MIT Computer Science and Artificial Intelligence Laboratory, the largest on-campus laboratory at MIT, where he also leads the Supertech research group. He is a Margaret MacVicar Faculty Fellow, the highest recognition at MIT for undergraduate

This research was supported in part by NSF Grants 1314547 and 1533644.

Permission to make digital or hard copies of part or all of this work for personal or classroom use is granted without fee provided that copies are not made or distributed for profit or commercial advantage and that copies bear this notice and the full citation on the first page. Copyrights for third-party components of this work must be honored. For all other uses, contact the owner/author(s).

SPAA '18, fuly 16-18, 2018, Vienna, Austria

(C) 2018 Copyright held by the owner/author(s).

ACM ISBN 978-1-4503-5799-9/18/07.

https://doi.org/10.1145/3210377. 3210378 teaching. He is a Fellow of four professional societies - AAAS, ACM, IEEE, and SIAM - and he is a member of the National Academy of Engineering. He has received many Best Paper awards at prestigious conferences, as well as the ACM-IEEE Computer Society Ken Kennedy Award, the IEEE Computer Society Taylor L. Booth Education Award, ACM Paris Kanellakis Theory and Practice Award, and the ACM and Hertz Foundation Doctoral Dissertation Awards.

Professor Leiserson's current research centers on software performance engineering: making computer programs run fast. His contributions include the Cilk multithreaded programming technology, which is available in many compilers today. He founded Cilk Arts, Inc., an MIT spinoff which was acquired by Intel Corporation. On leave from MIT as Director of System Architecture at Akamai Technologies, he led the engineering team that developed Akamai's worldwide content-

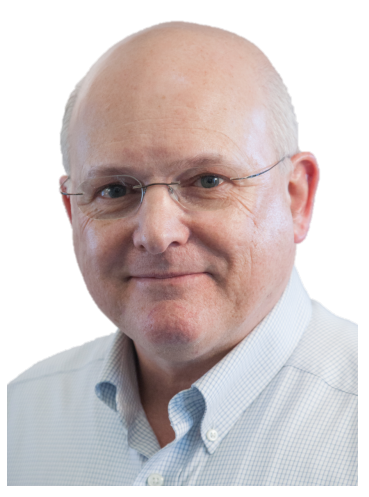
distribution network comprising tens of thousands of servers. He designed and led the implementation of the network architecture for Thinking Machine Corporation's Connection Machine CM-5, the world's most powerful supercomputer in the early 1990's, which incorporated the "universal" fat-tree interconnection network he conceived at MIT. He led the development of several Cilk-based parallel chess-playing programs, including $\star$ Socrates and Cilkchess, winning numerous prizes in international competition. He coauthored the first paper on systolic architectures, invented the retiming method of digital-circuit optimization, and introduced the notion of cache-oblivious algorithms. He is well known as coauthor of Introduction to Algorithms (MIT Press), the leading textbook on computer algorithms, which has sold almost 800,000 copies and is one of the most cited publications in computer science. His annual workshop on Leadership Skills for Engineering and Science Faculty has educated hundreds of faculty at MIT and around the world in the human issues involved in leading technical teams in academia. Professor Leiserson has supervised over two dozen Ph.D. students and more than 60 Master's and Bachelor's students. 